\title{
Palliative Care in Older People with Multimorbidities: A Scoping Review on the Palliative Care Needs of Patients, Carers, and Health Professionals
}

\author{
Laura Llop-Medina $^{1}(\mathbb{D}), \mathbf{Y u ~ F u}^{2}{ }^{(\mathbb{D})}$, Jorge Garcés-Ferrer ${ }^{1}(\mathbb{D})$ and Ascensión Doñate-Martínez ${ }^{1, *(\mathbb{D})}$ \\ 1 Polibienestar Research Institute, University of Valencia, 46022 Valencia, Spain; laura.llop@uv.es (L.L.-M.); \\ jordi.garces@uv.es (J.G.-F.) \\ 2 Population Health Sciences Institute, Newcastle University, Newcastle NE2 4AX, UK; yu.fu@newcastle.ac.uk \\ * Correspondence: ascension.donate@uv.es
}

check for updates

Citation: Llop-Medina, L.; Fu, Y.; Garcés-Ferrer, J.; Doñate-Martínez, A. Palliative Care in Older People with Multimorbidities: A Scoping Review on the Palliative Care Needs of Patients, Carers, and Health Professionals. Int. J. Environ. Res. Public Health 2022, 19, 3195. https:// doi.org/10.3390/ijerph19063195

Academic Editors: María José Cabañero-Martínez, Manuel Fernández Alcántara and Rafael Montoya Juárez

Received: 31 December 2021

Accepted: 3 March 2022

Published: 8 March 2022

Publisher's Note: MDPI stays neutral with regard to jurisdictional claims in published maps and institutional affiliations.

Copyright: (C) 2022 by the authors. Licensee MDPI, Basel, Switzerland. This article is an open access article distributed under the terms and conditions of the Creative Commons Attribution (CC BY) license (https:// creativecommons.org/licenses/by/ $4.0 /)$.

\begin{abstract}
Although numerous studies have been conducted previously on the needs of cancer patients at the end of their life, there is a lack of studies focused on older patients with non-oncological complex chronic multipathologies. Examining these needs would help to gain a greater understanding of the profile of this specific population within the palliative care (PC) pathway and how the health and care systems can address them. The aim of this review was to identify the needs influencing PC among older patients with multimorbidities, their relatives or informal caregivers, and the health professionals who provide care for these patients. A scoping literature review guided by the Systematic Reviews and Meta-Analyses extension for Scoping Reviews (PRISMA-ScR) checklist was carried out with literature searched in the Medline, Embase, CINAHL, WoS, Cochrane Library, PsycINFO, and Scopus databases from 2009 to 2022. Eighty-one studies were included, demonstrating a great variety of unaddressed needs for PC among chronic older patients and the complexity in detecting those needs and how to refer them to PC pathways. This review also suggested a scarcity of tools and limited pathways for professionals to satisfy their needs for these patients and their families, who often felt ignored by the system. Substantial changes will be needed in health and care systems at the institutional level, providing more specialized PC environments and systematizing PC processes.
\end{abstract}

Keywords: palliative care needs; older patients; multimorbidities; caregivers; health professionals

\section{Introduction}

The palliative care (PC) concept has undergone changes and evolution in related conceptual and strategic approaches, including their use in clinical practice, in recent years. Conceptually, in 1990, the World Health Organization (WHO) adopted the definition proposed by the European Association for Palliative Care (EAPC) as the total active care of patients whose disease does not respond to curative treatment. The control of pain and other symptoms, as well as psychological, social, and spiritual problems, is paramount. The WHO subsequently expanded this definition, currently taking the form of: "An approach that improves the quality of life of patients and families facing life-threatening diseases, preventing and mitigating suffering through early identification, pain assessment and treatment, and other physical, psychosocial and spiritual problems" [1].

According to this definition, the delivery of PC should be guided by the improvement in patients' and their families' quality of life. Additionally, PC aims at facing needs associated with life-threatening conditions and trying to prevent and relieve suffering through several actions in the continuum of care: early and timely identification, adequate assessment and treatment of multi-domain symptomatologies. PC is applicable at the onset of the disease, alongside other curative therapies. This integration of PC has been developed mostly around the oncology area as most of the PC protocols, programmes and units are 
more focused and addressed to patients with cancer. However, the rate of older adults (60 and over) in need of PC with non-oncological diseases, such as Chronic Obstructive Pulmonary Disease (COPD), diabetes, cardiovascular disease and renal diseases [2] among others, is higher than those with cancer [3], and additionally, when they are admitted to PC units they tend to be closer to death than those patients with cancer [4]. Several systematic reviews have reported that patients with advanced cancer experience improved quality of life and symptom intensity with early PC interventions compared to those who only received cancer care alone $[5,6]$. There are also numerous studies that have been previously conducted on the needs of cancer patients at the end of their life, such as Bandieri [7], Haun [5], and Wang [8], however there is a lack of studies focusing on older patients with non-oncological complex chronic multipathologies, therefore, this study has focused on the needs of this profile of patients.

Chronic diseases represent around $70 \%$ of deaths worldwide [9]. The increased incidence, prevalence, and mortality of chronic diseases and multimorbidities, defined as the presence of two or more long-term health conditions [10], place a significant challenge on PC resources and a burden on health policies and practices [11]. As an increase in the rate of older people with complex chronic diseases is expected over the next 25 years, early identification of PC needs among older patients with comorbidities is becoming an important concern to health systems [12] in order to provide comprehensive care that meets the needs of both patients and family caregivers, considered by the WHO as an indivisible unit in the provision of PC. Ensuring that family caregivers' needs are appropriately assessed is one of the top quality markers for end-of-life care [13], due to them being critical to the patients quality of life. Thus, the aim of this scoping review was to identify the PC needs of patients with multimorbidities (excluding cancer), their family caregivers and the professionals that work with these patients to obtain a global vision of the actors involved in the provision of PC. This study provides a comprehensive analysis of the needs and concerns around PC provision for non-oncological chronic conditions from a broad approach, joining perspectives of three target groups.

\section{Materials and Methods}

This scoping review used the framework of Arksey and O'Malley [14], which comprises five stages: identifying the research question; identifying relevant studies; study selection; charting the data; and collating, summarizing, and reporting the results. The Systematic Reviews and Meta-Analyses extension for Scoping Reviews (PRISMA-ScR) checklist was used to guide the conduct of this review, which contains 20 essential reporting items and two optional items to include when completing a scoping review [15]. The protocol of this scoping review has not been registered or published.

\subsection{Identifying Relevant Studies}

Thorough electronic searches were carried out in the Medline, Embase, Cumulative Index to Nursing and Allied Health Literature (CINAHL), Web of Science, Cochrane Library, PsycINFO, and Scopus databases covering the period January 2009 to February 2022. A range of keywords and subject headings indicating PC needs, older people's needs, patients, families, non-formal caregivers, and health care professionals were used to maximize the retrieval of relevant studies. The specific questions addressed within this review were:

- What are the PC needs for older patients with multimorbidities?

- What are the PC needs for caregivers of older patients with multimorbidities?

- What are the needs influencing PC provision by health professionals for older patients with multimorbidities and their caregivers?

The final search strategies used in Scopus are shown below as an example:

- $\quad(((($ palliative care [Title/Abstract]) AND patients [Title/Abstract]) AND needs [Title/Abstract]) OR preferences [Title/Abstract]) AND older [Title/Abstract] OR elderly [Title/Abstract]). 
- ((palliative care [Title/Abstract]) OR palliative care unit AND health professionals[Title/Abstract] AND perceptions [Title/Abstract]) OR needs [Title/Abstract]) NOT patients [Title/Abstract]).

- ((palliative care [Title/Abstract]) AND families [Title/Abstract] OR caregiver [Title/Abstract]) AND needs [Title/Abstract]) OR perceptions [Title/Abstract]) AND elderly [Title/Abstract]) OR aged [Title/Abstract]).

\subsection{Study Selection}

The records identified from the electronic searches were imported into Endnote (Reuters, 2011) to avoid duplication of the screening process. Titles and abstracts were initially screened (by L.L.-M., A.D.-M., or Y.F.) to identify potentially eligible papers, and doubts were resolved between those reviewers. The full texts of potentially eligible papers were independently screened against eligibility (see Table 1) criteria by three reviewers (L.L.-M., A.D.-M., or Y.F.). No additional manual searching was carried out.

Table 1. Inclusion and exclusion criteria.

\begin{tabular}{ccc}
\hline Criterion & Inclusion & Exclusion \\
\hline Period & 1 January 2009 until 7 February 2022 & Published before 2009 \\
\hline Language & English & Any other languages \\
\hline Type of studies & $\begin{array}{c}\text { Qualitative, quantitative, and mixed method studies } \\
\text { published in peer-reviewed journals }\end{array}$ & $\begin{array}{c}\text { Letters, comments, conference } \\
\text { abstracts, editorials, doctoral thesis }\end{array}$ \\
\hline Type of participants & Older patients with multimorbidity (presence of two or & Cancer patients \\
& Caregivers of older patients with multimorbidity & Patients who do not have \\
& Health professionals in any PC healthcare setting & $\begin{array}{c}\text { multimorbidity (presence of two or } \\
\text { more long-term health conditions) } \\
\text { Patients under 60 years of age }\end{array}$ \\
\hline Type of outcomes & Concerning Palliative care needs & Not concerning palliative care needs \\
\hline
\end{tabular}

The papers included were peer-reviewed studies published between 2009 and 2022, in the English language, using any research design to report the needs or concerns in PC of older patients with multimorbidity, their families or carers, and health professionals in any healthcare setting.

The papers excluded were those about PC focused on cancer, published before 2009, involving patients younger than 60 years old, covering aspects of care and treatment not related to PC, lack of availability of full text, or full text available but paper written in any language other than English.

\subsection{Charting the Data}

Data were extracted employing a structured data extraction form that was tested in a sample of 5 studies by three members of the research team independently (L.L.-M., A.D.-M., or Y.F.) and were double-checked by a second reviewer (L.L.-M. or A.D.-M.). Data were extracted first by identifying the target groups involved (patients, caregivers, and health professionals). Secondly, data extraction was performed in a descriptive manner according to the following variables: Age group of patients, country of the study, source of data collection, type of service, care setting, main thematic findings, and reported limitations (see Supplementary Materials, Table S1).

\subsection{Collating, Summarizing and Reporting the Results}

Based on the data extracted, the included studies were classified according to the WHO's PC definition. Final topics were agreed by three members of the research team. These final topics are presented in Table 2 below. 
Table 2. Final topics according to the WHO's PC definition.

\begin{tabular}{ccc}
\hline Patients & Caregivers & Professionals \\
\hline Emotional/mental needs & Emotional/mental needs & \\
Physical needs & Physical needs & PC provision \\
Information needs & Social needs & Training needs \\
Spiritual needs & Financial needs & \\
Other needs & Other needs & \\
\hline
\end{tabular}

Due to the studies collected presenting a range of diverse methodologies, an exhaustive analysis of the quality of the studies was not carried out. However, the limitations of each of the studies included, if these were reported, are listed in the extraction table.

\section{Results}

A total of 6162 records were identified covering the time span of January 2009 to February 2022. From them, 642 records were selected for abstract review, identifying 81 final studies for full review. The process of the study selection is detailed in the PRISMA flow diagram (Figure 1).

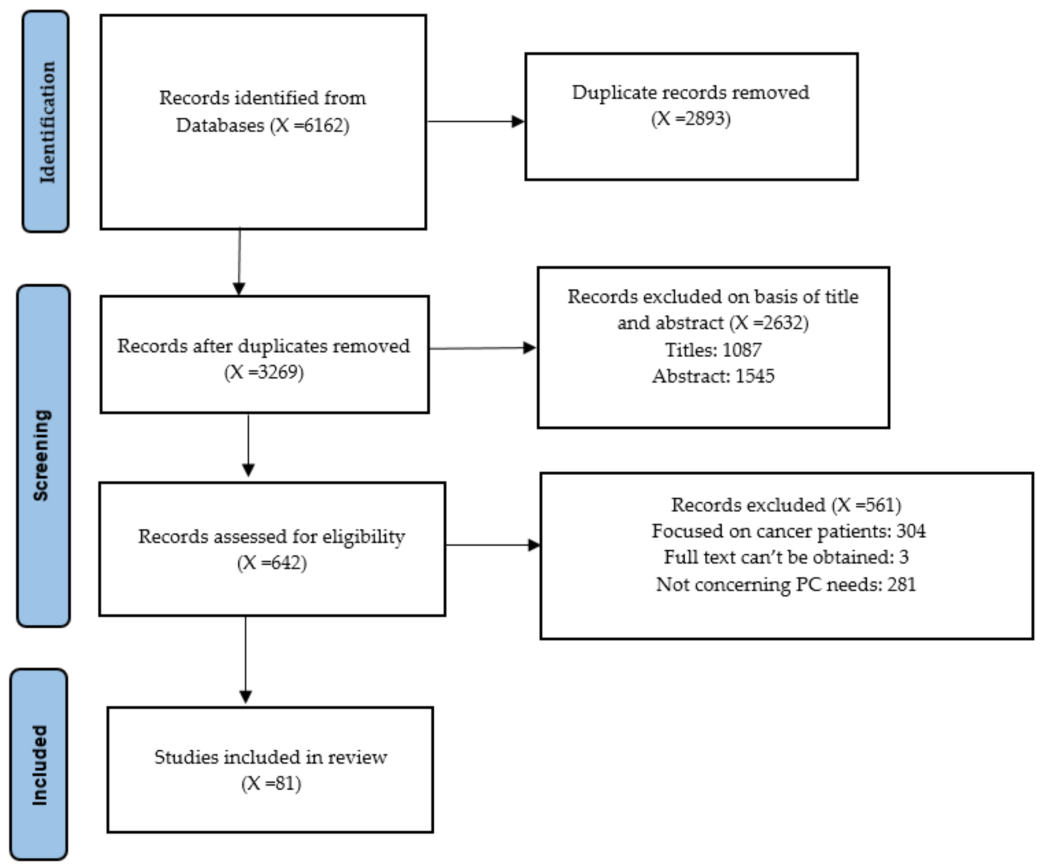

Figure 1. Study selection Prisma Flow Diagram.

Although most of the papers analysed focus on a single country (51), a great deal of heterogeneity has been detected in studies addressing two or more countries. Next is detailed the distribution of studies by country. Most of the studies included were conducted in the UK [16-35], the USA [36-44], Australia [45-53], Canada [54-60], and Germany [61-66]. Some studies were performed in two or more countries: Belgium, Netherlands, UK, Germany, Hungary [67]: North America, Australia [68], UK, Ireland, USA [69], USA, UK, Australia, Canada, Belgium, Germany, Hong Kong, Japan, Malaysia, Singapore [70], USA, UK, Sweden, Netherlands, Spain, Canada, Ireland, Australia, New Zealand [71], South Africa, Kenya, South Korea, United States, Canada, UK, Belgium, Finland, Poland [72], Australia, New Zealand, UK [73], Canada, USA, UK [74]. The rest were in Belgium [75,76], Sweden [77-79], Brazil [80], China [81], Switzerland [82], the Netherlands [83,84], Norway [85], New Zealand [86], Denmark [87] and Hong Kong [88]. There were six studies with no information on the country/city where the research was performed [89-96]. 
Regarding the sources of data collection, the sources of data collection of all the studies analysed in the review are detailed in the following table (see Table 3).

Table 3. Sources of data collection.

\begin{tabular}{|c|c|}
\hline Sources of Data & References \\
\hline Individual Interviews & $\begin{array}{l}{[18,26,27,32,44,46,48,58,59,62,63,76,77,80,82,90 \text {, }} \\
92]\end{array}$ \\
\hline Focus groups & {$[17,18,25,48,50,51,57,61,64,72,75,78,86]$} \\
\hline $\begin{array}{l}\text { Individual interview and focus group or } \\
\text { similar }\end{array}$ & {$[22,24,28,33,35,36,42,47,49,53,85,87]$} \\
\hline $\begin{array}{l}\text { Individual interview and questionnaire or } \\
\text { survey }\end{array}$ & {$[65,81]$} \\
\hline Survey or questionnaire & {$[30,34,37-39,52,56,66,69,73,83]$} \\
\hline Reviews & {$[34,62,64,65,68,80,82,84]$} \\
\hline $\begin{array}{l}\text { Individual interview, focus group or similar } \\
\text { and survey }\end{array}$ & {$[20,31,54,60]$} \\
\hline $\begin{array}{l}\text { Individual interview focus group or similar } \\
\text { and survey and RTC }\end{array}$ & [21] \\
\hline Individual interview, ethnographic observation & {$[29,41]$} \\
\hline $\begin{array}{l}\text { Non-participant observation, semi-structured } \\
\text { interviews, focus groups and a co-design event }\end{array}$ & [19] \\
\hline $\begin{array}{l}\text { Individual interview, retrospective audit of } \\
\text { existing hospital databases }\end{array}$ & [45] \\
\hline $\begin{array}{l}\text { Q-methodology (combination of qualitative } \\
\text { and quantitative techniques) }\end{array}$ & [94] \\
\hline
\end{tabular}

Most of the studies (69.9\%) focused on the perspective of one cohort: professionals $(47.4 \%)$, relatives or caregivers $(13.1 \%)$ and patients $(9.4 \%)$, while the rest reported the needs of combined cohorts: patients, caregivers, and professionals (13.1\%), on patients and caregivers $(13.1 \%)$, and patients and professionals $(3.9 \%)$.

Taking into account whether the studies can refer to several targets, some studies made reference to various targets, 31 addressed the perspective of patients, 31 addressed the perspective of caregivers and 53 analysed the perspective of professionals.

Studies included were undertaken in different health care settings: inpatient care (52.7\%) [16-18,21,22,24,26,27,29-32,34,37,38,40,42-44,47-49,54,57,59,60,62,67,68,72,74,77,78,80, $82,83,85,91-93]$ outpatient care (18.5\%) [28,33,35,36,39,45,46,52,53,64,68,73,86,87], and combined inpatient and outpatient care $(21.2 \%)[20,25,41,50,56,61,63,65,66,69-71,76,81,89,90]$. In addition, five studies $(6.7 \%)$ did not specify the care setting $[19,23,58,75,94]$.

\subsection{Patients' Needs}

Of the studies, 31 addressed the PC needs of multimorbid older patients only or together with other cohorts.

\subsubsection{Emotional/Mental Needs}

Most of the needs reported were related to emotional and/or mental dimensions, such as social isolation, depression, anxiety, or feeling like a burden on families $[18,28,34,39,41,69,71,91]$.

\subsubsection{Physical Needs}

Patients reported that needs at the physical level caused less concern, as they were often considered covered by health providers through therapies or treatments. However, 
the most commonly reported physical needs were pain, fatigue, restlessness and agitation, and limitations in activities of daily living $[18,34,39]$.

\subsubsection{Information Needs}

A lack of enough information was also reported in several studies, highlighting the need for more information about PC and related resources $[19,21,55,70,83,92]$, as well as the need for information about the progression and severity of their disease $[63,70,71,89,95]$. In line with information gaps, communication with health providers was also detected as an area for improvement, as patients consider it necessary to improve relationships and effective communication, for instance, to feel more supported in finding PC providers [39-41,49,71,74,89,95].

\subsubsection{Spiritual Needs}

Some studies revealed the need for spiritual care $[33,41,45,48,71,72,96]$, although these were approached from different perspectives, with some studies mentioning the need for spiritual attention without specifying more about it $[33,48,71]$ and others referring to more specific aspects of this concept. In this sense, patients can feel distress if their religious wishes and values are not attended to, and being able to discuss spiritual beliefs was indicated as highly important to many patients [41]. Patients felt that clinicians lacked knowledge about cultural practices, such as rituals and religious aspects considered highly sensitive and necessary in end-of-life care $[45,72,96]$. In some cases, spiritual care was considered to be the possibility of talking to religious leaders, or as providing a safe space, communicating with sensitivity about spirituality, listening, and counselling [72].

\subsubsection{Other Needs}

Other needs, such as specific cultural needs, were also mentioned, as well as clinicians' lack of cultural awareness and the potential breadth of cultural practices, rituals, and other cultural patient's needs [45].

The need for an adequate environment, with privacy and dignity, as well as the preference for receiving care in the same place and by the same clinicians in order to become comfortable with the environment and to minimize distress, especially in cases of patients with dementia, were also reported $[33,48,74,83,94]$. Moreover, the appointment of a key worker acting as a point of contact for the patient and family was considered relevant for continuity of care, avoiding confusion, and maintaining continuous contact [20].

\subsection{Caregivers' Needs}

Thirty-one of the studies addressed relatives' or informal caregivers' PC needs, together with other target groups in some cases.

\subsubsection{Emotional/Mental Needs}

Similarly, to patients, some of the needs pointed out in the studies by caregivers were those related to emotional and/or mental aspects, such as sleep problems, stress, confinement, physical strain, or anxiety $[44,57,95]$. They also desired emotional support and educational courses regarding how to handle emergency situations, e.g., falls and psychosis or medications, and more information about disease progression and what to expect in the future $[35,36,56,65]$.

\subsubsection{Physical Needs}

Caregivers indicated the need for more respite services or personal outings to deal with fatigue and strain $[35,57]$.

\subsubsection{Financial Needs}

Other needs related to financial concerns were also mentioned in some of the studies. Some caregivers had to leave their paid employment to provide full-time care and use their 
savings or accumulate debt derived from paying for care for their family member, the costs associated with long-distance travel, medications, home care, accommodation, and the rental of equipment necessary for the care of the patient's needs $[36,39,44,49,58,74]$.

\subsubsection{Social Needs}

Social needs were also detected in those studies related to the impact of caring on caregivers' social life. These studies stressed the loss of and decrease in caregivers' social contacts or the experience of isolation from friends, neighbours, and the community as a result of providing full-time care $[18,36,44,58]$. Social assistance needs to obtain resources or benefits, such as direct financial support or social services to alleviate the burden of care, were also mentioned $[36,41,58]$.

\subsubsection{Other Needs}

Some studies reported that family caregivers felt that the amount and type of information received about their patients' health were inadequate and insufficient $[36,51,55,65,91,95]$. Some studies pointed out that caregivers consider care providers to be mainly focused on the medical aspects of care and that they tend to exclude the psychological, emotional, practical, and spiritual domains $[41,58,72]$. In this line, spiritual care was reportedly lacking, due to staff members' lack of time and their lack of prioritization of this aspect of care; consequently, caregivers reported the need for spiritual care for patients and themselves and the need to have time to talk to clinicians about this $[33,35,51,56,93]$. Furthermore, more time and human connection with professionals, effective communication, and shared decision making were indicated as important $[30,55,56,91]$.

Some studies reported that caregivers feel that they do not have enough information about PC services and how these can provide more comfortable care $[20,29,56,68,84,91]$. Regarding discussing end-of-life care preferences together with healthcare staff, some studies reported that family members would like to be more involved in medical decisions $[74,93,95]$. Caregivers often felt that medical staff, such as nurses or doctors, do not have enough time to listen to and discuss their relative's condition with them, becoming a source of distress to families who feel under pressure to make the right choices [33]. One study emphasized concerns about combining work with caring for their family member, highlighting the need for remote working and flexibility in working hours [84]

Lastly, other studies highlighted bereavement support as an important need for caregivers. Carers described the continued need for support in the period soon after death $[33,56,84]$, and remarked that palliative care provision should be extended to support family carers $[20,35,56,58]$.

\subsection{Professionals' Needs}

Fifty-three studies focused on professionals only, or together with other target groups, to approach PC. Two main domains were found: The needs and concerns of professionals in the provision of PC for multimorbid older patients and needs related to specific training in PC provision.

\subsubsection{Needs in PC Provision}

On the one hand, professionals identified barriers to providing effective PC to this group of patients. In some studies, professionals pointed out that patients with nonmalignant disease were less likely to be referred to PC services due to the historical link between cancer and palliative care $[24,25,66]$. In other studies, professionals highlighted that patients suffering from non-cancer diseases often receive inadequate care, with poor communication between the different services that care for them, and also shared that there are fewer specific services for these patients compared to for cancer patients [61,83]. A lack of staff to provide sufficient care to patients, resulting in little time to properly address PC needs, was highlighted by some studies [48,79-81]. 
(a) Referral to PC

Often, multimorbid patients are referred to PC units in the terminal stages of their disease; thus, professionals consider it necessary to initiate these referrals earlier to promote continuous care [78,85], especially with older patients [61], patients with Chronic Heart Failure (CHF) and COPD [75,76], and patients with conditions other than cancer [25]. Moreover, professionals do not always know who has the responsibility to care for CCC patients in need of PC, and often the roles are not defined, which causes fear of starting conversations about palliative care with the family or the patient $[26,60,66,90]$.

In this sense, some of the studies showed a lack of homogeneous referral criteria, protocols, or pathways to initiate PC services $[31,52,67,76]$. Additionally, professionals pointed out that there are barriers to referring PC patients and interspecialty dialogue, with a lack of communication between different specialists resulting in professionals only partially knowing the pathologies that can occur in patients and preventing or delaying referral to a PC itinerary [46].

Moreover, in some studies, professionals expressed that there is complexity in prescription and treatment approaches due to the impact of the complex comorbidity profiles of multimorbid patients, such as the effects of drugs in older populations (unforeseeable interactions or side effects) [61,90].

(b) Comprehensive and continuous care in PC

Professionals considered that a holistic approach to patient care is crucial, starting when curative treatment is no longer realistic, rather than focusing only on physical symptoms $[16,21,76,79,88]$. The necessity of going beyond the management of pain was underlined, as patients' and their relatives' non-physical needs, such as spiritual and emotional needs, were considered to need further support [16,76].

Some studies also pointed out that professionals need more time and continuity in the attention given to their patients, having time to talk calmly with patients and their families about PC decisions and needs $[31,62,81,82,87]$. The pressure of having less time was indicated as causing a feeling of not being able to talk with or attend to patients in a comprehensive way $[62,82]$, and lack of continuity was pointed out as a major threat to PC attention, especially for people with severe dementia [32,79,85]. Two studies remarked on the need to take into consideration the biography of each patient, and reported that practitioners considered that they only overviewed fragments of care among older patients, which makes the provision of individualized care adapted to patients' needs difficult [52,61].

Some studies also remarked that adequate time is not available for professionals to be able to start conversations with relatives and patients about care planning and advanced directives [66,76]. Two studies stressed that professionals lack knowledge and belief in the role of advanced plans, since many changes can take place in the medium and long term $[27,85]$. It was also pointed out that there is a need for an objective measure to identify caregivers at risk of poor bereavement $[50,53]$ and dedicated staff to take responsibility for bereavement care [50,57]. Furthermore, a need for formal assessments of bereavement instead of using only observations, intuitions, or informal conversations was highlighted [50].

A proactive multidisciplinary approach (combining clinical psychologists, social workers, and psychiatrists) and interprofessional collaboration $[24,66,71,78]$ were described as important in PC to increase CCC patients' and their caregivers' wellbeing [52,67,73,81,86,90]. Moreover, new specialized structures for PC geriatric patients were considered necessary to be able to address the specific needs of patients with multiple needs [61].

\subsubsection{Training Needs}

On the contrary, several training needs were detected. Special reference was made to specialized training in PC, highlighting that professionals may feel they have a lack of skills for good communication with patients [89], the need for additional palliative and end-of-life care education $[19,38,80,86]$, more awareness and understanding of PC, as well as further training on how to identify patients' needs and understanding of end-of-life care [66,81]. 
Additionally, several studies highlighted the lack of knowledge of the palliative needs of different groups of patients, such as those with COPD [87], severe dementia [18,68], disabilities [31], or complex comorbidity profiles [46]. Some studies stated the need to move toward early PC conception, as many professionals recognized that their perception of PC was associated with care during the last days of life $[22,29,47]$. Furthermore, one study highlighted the need for advanced training in early PC [75].

Some studies also pointed out professionals needing emotional support to prevent burnout and delineating emotional and professional boundaries [43]. One study highlighted the need for self-care in coping with death and dealing with professional grief [31], as some professionals felt that their grief is inappropriate or that they do not have time to express it [27].

In this line also, healthcare professionals remarked on the importance of spiritual care and having the skills to address it $[16,73]$. However, it was pointed out that professionals felt fear of being unable to resolve spiritual problems and experienced difficulties in communication about spiritual needs due to a lack of knowledge around such issues [17,96]. Additionally, they highlighted that assessment tools for spiritual needs are not taught during the received training $[17,96]$. Moreover, practitioners and nurses indicated a desire for support to address patients' spiritual needs from other professionals, such as social workers, clinical/counselling psychologists, chaplains/spiritual care professionals, other alternative therapy professionals, and psychiatric professionals [81].

\section{Discussion}

This review contributes to a greater understanding of the needs of three cohorts involved in PC: older patients with non-malignant diseases, their family members or caregivers, and the health professionals delivering care for them. Integration of needs reported by them enabled a more comprehensive understanding of PC needs than those that focused on a single cohort only. Moreover, this review synthesized the needs for these three groups, which are very complex, diverse, and heterogeneous.

The studies included presented the support needed by patients related to their emotional/mental health, such as symptoms or experiences related to anxiety and depression. Supporting needs to address their clinical symptoms and to maintain their daily living activities was highlighted, and some studies also discussed patients' concerns about the potential burden that their families or caregivers may experience as a consequence of covering their care needs. The needs identified in caregivers mirrored those identified at the patient level, but emphasized bereavement support, need of more information and human connection with professional's involvement in decision making and financial support to care for both patients and themselves. It is worth highlighting that patients and caregivers noticed a lack of support in their psychosocial and spiritual needs, while considering their physical needs as being well-addressed.

In line with the results reported by Mathews et al. [97], where the integration of specialized palliative care with oncology patients was analysed, health professionals agreed that integrated PC services are the desired care models to facilitate integration and coordination of care using an interdisciplinary approach $[74,77,78]$. This study also highlighted the need to allocate more personnel, time, and training to assessing and addressing the needs of oncological patients and their families or caregivers, as identified in our review. Our review also highlighted the need for health professionals' training in palliative care across all services (primary care, ICU, residences, emergencies, home hospitalization units), especially for providing care to non-cancer patients, as well as the need for itineraries and defined responsibilities in PC and more time to attend patients holistically and discuss with family members their needs and wishes $[16,35,61,76]$.

The follow-up of grief for caregivers was highlighted as an urgent issue, with professionals considering it neglected $[47,50,53]$. To substantially improve the holistic attention provided for caregivers and relatives of CCC patients, it is essential to establish mechanisms 
to identify people at risk of complex grief and to have time and qualified personnel to deal with this issue within the context of PC.

Both patients and caregivers highlighted the need for spiritual care $[33,35,39,73]$, but professionals felt a lack of knowledge and skills around related issues [16,17,37]. Moreover, there is no unanimity about what spiritual care means $[21,26,61,96]$. This is in line with the results of Gijsberts et al. [98], and considering the positive effects of spiritual care reported on patients, this dimension of care needs to be more visible.

This scoping review followed a systematic method and examined a wide range of studies that included three different perspectives (patients, relatives/informal caregiver, and healthcare professionals). This approach allowed for a complete and holistic view of the experiences and needs of older patients with multimorbidities at PC pathways. However, there are some limitations in this review. First, the study only included studies published in the English language; thus, some relevant studies could have been excluded. Moreover, we did not perform manual searching of key journals, and grey literature was not included, as we carried out searches in seven commonly used databases. This review it is not intended to establish definitive conclusions about all the needs of the target groups, as it is a scoping review and the intention of the study has been to make a first approach to them, since the research questions were very broad. We sought to map the needs detected in the literature for the three target groups with the aim of being able to deepen them in future studies. As this is a scoping review, no risk of bias assessment was conducted. In addition, we can only extract results of the studies with available data, acknowledging the limitations of the analysed studies, including issues such as the exclusion of some countries if studies were not published in English language. However, we consider there to be sufficient accuracy and consistency of the results analysed in this scoping review for it to be useful to guide future research.

\section{Conclusions}

This review provided evidence highlighting that substantial changes are needed in health and care systems at the institutional level to provide more specialized PC environments and systematized PC processes for multimorbid older patients. It is vital to understand and address the needs of multimorbid older patients and their caregivers given that the number of these patients is growing, which may challenge current healthcare systems. Regarding clinical practice, the identification of older chronic patients in need of PC will allow healthcare professionals to plan care and pathways in advance, and to reduce unnecessary admissions to emergency departments. Therefore, a systematic assessment of needs through appropriate tools in clinical practice is necessary to enable the development of an individualized integrated PC model for patients with complex PC needs. These findings can guide policymakers in increasing investment in specialized PC services focused on multimorbid patients to support more efficient use of available resources for healthcare professionals in their routine practice. For future studies, it is recommended to take into consideration patients comorbidities, since their needs vary accordingly, as well as the particular requirements around PC of those older people with COVID-19.

Supplementary Materials: The following supporting information can be downloaded at: https: / / www.mdpi.com/article/10.3390/ijerph19063195/s1, Table S1: Data extraction table.

Author Contributions: Conceptualization, L.L.-M. and A.D.-M.; methodology, L.L.-M., A.D.-M. and Y.F.; analysis, L.L.-M., Y.F. and A.D.-M.; manuscript writing, L.L.-M. and A.D.-M.; critical review, Y.F. and J.G.-F. All authors have read and agreed to the published version of the manuscript.

Funding: This project received funding from the European Union's Horizon 2020 research and innovation program under grant agreement number 825750 and Grant PID2019-110997RB-I00 funded by MCIN/AEI/10.13039/501100011033.

Institutional Review Board Statement: Not applicable.

Informed Consent Statement: Not applicable. 
Data Availability Statement: No applicable.

Acknowledgments: The authors thank the whole InAdvance consortium for their contributions.

Conflicts of Interest: The authors declare no conflict of interest.

\section{References}

1. WHO. WHO Definition of Palliative Care. 2007. Available online: http://www.who.int/cancer/palliative/definition/en/ (accessed on 22 December 2020).

2. Wong, M.; Ho, L.; Hui, E.; Miaskowski, Y. Burden of living with multiple concurrent symptoms in patients with end-stage renal disease. J. Clin. Nurs. 2020, 29, 2589-2601.

3. Connor, S.R.; Bermedo, M.S. Global Atlas of Palliative Care at the End of Life. January 2014. Available online: http://www. thewhpca.org/resources/global-atlas-on-end-of-life-care (accessed on 30 December 2021).

4. Downar, J.; Chou, Y.C.; Ouellet, D.; La Delfa, I.; Blacker, S.; Bennett, M.; Petch, C.; Cheng, S.M. Survival duration among patients with a noncancer diagnosis admitted to a palliative care unit: A retrospective study. J. Palliat. Med. 2012, 15, 661-666. [CrossRef] [PubMed]

5. Haun, M.W.; Estel, S.; Rücker, G.; Friederich, H.; Villalobos, M.; Thomas, M.; Hartmann, M. Early palliative care for adults with advanced cancer. Cochrane Database Syst. Rev. 2017, 6, CD011129. [CrossRef] [PubMed]

6. Hui, D.; Kim, Y.J.; Park, J.C.; Zhang, Y.; Strasser, F.; Cherny, N.; Kaasa, S.; Davis, M.P.; Bruera, E. Integration of oncology and palliative care: A systematic review. Oncologist 2015, 20, 77-83. [CrossRef] [PubMed]

7. Bandieri, E.; Sichetti, D.; Romero, M.; Fanizza, C.; Belfiglio, M.; Buonaccorso, L.; Artioli, F.; Campione, F.; Tognoni, G.; Luppi, M. Impact of early access to a palliative/supportive care intervention on pain management in patients with cancer. Ann. Oncol. 2012, 23, 2016-2020. [CrossRef]

8. Wang, T.; Molassiotis, A.; Chung, B.P.M.; Tan, J.Y. Unmet care needs of advanced cancer patients and their informal caregivers: A systematic review. BMC Palliat. Care 2018, 17, 96. [CrossRef]

9. WHO. Noncommunicable Diseases; WHO: Geneva, Switzerland, 2017; Available online: https://www.who.int/news-room/factsheets / detail/noncommunicable-diseases (accessed on 22 December 2020).

10. Johnston, M.; Crilly, M.; Black, C.; Prescott, G.J.; Mercer, S. Defining and measuring multimorbidity: A systematic review of systematic reviews. Eur. J. Public Health 2019, 29, 182-189. [CrossRef]

11. Prince, M.J.; Wu, F.; Guo, Y.; Robledo, L.M.G.; O'Donnell, M.; Sullivan, R.; Yusuf, S. The burden of disease in older people and implications for health policy and practice. Lancet 2015, 385, 549-562. [CrossRef]

12. Kingston, A.; Robinson, L.; Booth, H.; Knapp, M.; Jagger, C. MODEM Project. Projections of multi-morbidity in the older population in England to 2035: Estimates from the Population Ageing and Care Simulation (PACSim) model. Age Ageing 2018, 47, 374-380. [CrossRef]

13. Saunders, C. End of Life Care Strategy: Quality Markers and Measures for End of Life Care; Department of Health: London, UK, 2009.

14. Arksey, H.; O'Malley, L. Scoping studies: Towards a methodological framework. Int. J. Soc. Res. Methodol. 2005, 8, 19-32. [CrossRef]

15. Tricco, A.C.; Lillie, E.; Zarin, W.; O’Brien, K.K.; Colquhoun, H.; Levac, D.; Moher, D.; Peters, M.D.; Horsley, T.; Weeks, L.; et al. PRISMA Extension for Scoping Reviews (PRISMAScR): Checklist and Explanation. Ann. Intern. Med. 2018, 169, 467-473. [CrossRef] [PubMed]

16. O'Brien, M.R.; Kinloch, K.; Groves, K.E.; Jack, B.A. Meeting patients' spiritual needs during end-of-life care: A qualitative study of nurses' and healthcare professionals' perceptions of spiritual care training. J. Clin. Nurs. 2019, 28, 182-189. [CrossRef] [PubMed]

17. Abbas, S.Q.; Dein, S. The difficulties assessing spiritual distress in palliative care patients: A qualitative study. Ment. Health Relig. Cult. 2011, 14, 341-352. [CrossRef]

18. Bajwah, S.; Higginson, I.J.; Ross, J.R.; Wells, A.U.; Birring, S.S.; Riley, J.; Koffman, J. The palliative care needs for fibrotic interstitial lung disease: A qualitative study of patients, informal caregivers and health professionals. Palliat. Med. 2013, 27, 869-876. [CrossRef]

19. Blackwell, R.W.; Lowton, K.; Robert, G.; Grudzen, C.; Grocott, P. Using Experience-based Co-design with older patients, their families and staff to improve palliative care experiences in the Emergency Department: A reflective critique on the process and outcomes. Int. J. Nurs. Stud. 2017, 68, 83-94. [CrossRef]

20. Bone, A.E.; Morgan, M.; Maddocks, M.; Sleeman, K.E.; Wright, J.; Taherzadeh, S.; Ellis-Smith, C.; Higginson, I.J.; Evans, C.J. Developing a model of short-term integrated palliative and supportive care for frail older people in community settings: Perspectives of older people, carers and other key stakeholders. Age Ageing 2016, 45, 863-873. [CrossRef]

21. Buckingham, S.; Kendall, M.; Ferguson, S.; MacNee, W.; Sheikh, A.; White, P.; Worth, A.; Boyd, K.; Murray, S.A.; Pinnock, H. HELPing older people with very severe chronic obstructive pulmonary disease (HELP-COPD): Mixed-method feasibility pilot randomised controlled trial of a novel intervention. Npj Prim. Care Respir. Med. 2015, 25, 15020. [CrossRef]

22. Davies, N.; Maio, L.; Vedavanam, K.; Manthorpe, J.; Vernooij-Dassen, M.; Iliffe, S.; IMPACT Research Team. Barriers to the provision of high-quality palliative care for people with dementia in England: A qualitative study of professionals' experiences. Health Soc. Care Community 2014, 22, 386-394. [CrossRef] 
23. Fleming, J.; Farquhar, M.; Brayne, C.; Barclay, S.; Cambridge City over-75s Cohort (CC75C) Study Collaboration. Death and the oldest old: Attitudes and preferences for end-of-life care-qualitative research within a population-based cohort study. PLoS ONE 2016, 11, e0150686. [CrossRef]

24. Gardiner, C.; Cobb, M.; Gott, M.; Ingleton, C. Barriers to providing palliative care for older people in acute hospitals. Age Ageing 2011, 40, 233-238. [CrossRef]

25. Gott, M.; Ingleton, C.; Bennett, M.I.; Gardiner, C. Transitions to palliative care in acute hospitals in England: Qualitative study. BMJ 2011, 342, d1773. [CrossRef] [PubMed]

26. Handley, M.; Goodman, C.; Froggatt, K.; Mathie, E.; Gage, H.; Manthorpe, J.; Barclay, S.; Crang, C.; Iliffe, S. Living and dying: Responsibility for end-of-life care in care homes without on-site nursing provision-A prospective study. Health Soc. Care Community 2014, 22, 22-29. [CrossRef] [PubMed]

27. Livingston, G.; Pitfield, C.; Morris, J.; Manela, M.; Lewis-Holmes, E.; Jacobs, H. Care at the end of life for people with dementia living in a care home: A qualitative study of staff experience and attitudes. Int. J. Geriatr. Psychiatry 2012, 27, 643-650. [CrossRef]

28. Lloyd, A.; Kendall, M.; Starr, J.M.; Murray, S.A. Physical, social, psychological and existential trajectories of loss and adaptation towards the end of life for older people living with frailty: A serial interview study. BMC Geriatr. 2016, 16, 176. [CrossRef] [PubMed]

29. Mason, B.; Epiphaniou, E.; Nanton, V.; Donaldson, A.; Shipman, C.; Daveson, B.A.; Harding, R.; Higginson, I.; Munday, D.; Barclay, S.; et al. Coordination of care for individuals with advanced progressive conditions: A multi-site ethnographic and serial interview study. Br. J. Gen. Pract. 2013, 63, e580-e588. [CrossRef] [PubMed]

30. Mayland, C.R.; Mulholland, H.; Gambles, M.; Ellershaw, J.; Stewart, K. How well do we currently care for our dying patients in acute hospitals: The views of the bereaved relatives? BMJ Support. Palliat. Care 2017, 7, 316-325. [CrossRef] [PubMed]

31. McLaughlin, D.; Barr, O.; McIlfatrick, S.; McConkey, R. Developing a best practice model for partnership practice between specialist palliative care and intellectual disability services: A mixed methods study. Palliat. Med. 2014, 28, 1213-1221. [CrossRef]

32. Lee, R.P.; Bamford, C.; Exley, C.; Robinson, L. Expert views on the factors enabling good end of life care for people with dementia: A qualitative study. BMC Palliat. Care 2015, 14, 32. [CrossRef]

33. Poole, M.; Bamford, C.; McLellan, E.; Lee, R.P.; Exley, C.; Hughes, J.C.; Harrison-Dening, K.; Robinson, L. End-of-life care: A qualitative study comparing the views of people with dementia and family carers. Palliat. Med. 2018, 32, 631-642. [CrossRef]

34. Ryan, T.; Ingleton, C.; Gardiner, C.; Parker, C.; Gott, M.; Noble, B. Symptom burden, palliative care need and predictors of physical and psychological discomfort in two UK hospitals. BMC Palliat. Care 2013, 12, 11. [CrossRef]

35. Waldron, M.; Kernohan, W.G.; Hasson, F.; Foster, S.; Cochrane, B. What Do Social Workers Think about the Palliative Care Needs of People with Parkinson's Disease? Br. J. Soc. Work 2013, 43, 81-98. [CrossRef]

36. Boersma, I.; Jones, J.; Coughlan, C.; Carter, J.; Bekelman, D.; Miyasaki, J.; Kutner, J.; Kluger, B. Palliative care and Parkinson's disease: Caregiver perspectives. J. Palliat. Med. 2017, 20, 930-938. [CrossRef] [PubMed]

37. Chang, E.; Daly, J.; Johnson, A.; Harrison, K.; Easterbrook, S.; Bidewell, J.; Stewart, H.; Noel, M.; Hancock, K. Challenges for professional care of advanced dementia. Int. J. Nurs. Pract. 2009, 15, 41-47. [CrossRef] [PubMed]

38. Cimino, N.M.; Lockman, K.; Grant, M.; McPherson, M.L. Knowledge, Skills, and Attitudes in Caring for Older Adults with Advanced Illness among Staff Members of Long-Term Care and Assisted Living Facilities: An Educational Needs Assessment. Am. J. Hosp. Palliat. Med. 2016, 33, 327-334. [CrossRef] [PubMed]

39. Grudzen, C.R.; Richardson, L.D.; Morrison, M.; Cho, E.; Morrison, R.S. Palliative care needs of seriously ill, older adults presenting to the emergency department. Acad. Emerg. Med. 2010, 17, 1253-1257. [CrossRef] [PubMed]

40. Hall, S.; Kolliakou, A.; Petkova, H.; Froggatt, K.; Higginson, I.J. Interventions for improving palliative care for older people living in nursing care homes. Cochrane Database Syst. Rev. 2011, 3, CD007132. [CrossRef]

41. Tallman, K.; Greenwald, R.; Reidenouer, A.; Pantel, L. Living with advanced illness: Longitudinal study of patient, family, and caregiver needs. Perm. J. 2012, 16, 28. [CrossRef]

42. Kwak, J.; Ko, E.; Kramer, B.J. Facilitating advance care planning with ethnically diverse groups of frail, low-income elders in the USA: Perspectives of care managers on challenges and recommendations. Health Soc. Care Community 2014, 22, 169-177. [CrossRef]

43. Perez, G.K.; Haime, V.; Jackson, V.; Chittenden, E.; Mehta, D.H.; Park, E.R. Promoting resiliency among palliative care clinicians: Stressors, coping strategies, and training needs. J. Palliat. Med. 2015, 18, 332-337. [CrossRef]

44. Thai, J.N.; Barnhart, C.E.; Cagle, J.; Smith, A.K. "It Just Consumes Your Life": Quality of Life for Informal Caregivers of Diverse Older Adults With Late-Life Disability. Am. J. Hosp. Palliat. Med. 2016, 33, 644-650. [CrossRef]

45. Bloomer, M.J.; Botti, M.; Runacres, F.; Poon, P.; Barnfield, J.; Hutchinson, A.M. Cultural considerations at end of life in a geriatric inpatient rehabilitation setting. Collegian 2019, 26, 165-170. [CrossRef]

46. Broom, A.; Kirby, E.; Good, P.; Wootton, J.; Adams, J. Specialists' experiences and perspectives on the timing of referral to palliative care: A qualitative study. J. Palliat. Med. 2012, 15, 1248-1253. [CrossRef] [PubMed]

47. Chang, E.; Bidewell, J.; Hancock, K.; Johnson, A.; Easterbrook, S. Community palliative care nurse experiences and perceptions of follow-up bereavement support visits to carers. Int. J. Nurs. Pract. 2012, 18, 332-339. [CrossRef] [PubMed]

48. Fleming, R.; Kelly, F.; Stillfried, G. 'I want to feel at home': Establishing what aspects of environmental design are important to people with dementia nearing the end of life. BMC Palliat. Care 2015, 14, 26. [CrossRef] [PubMed] 
49. Lewis, E.T.; Harrison, R.; Hanly, L.; Psirides, A.; Zammit, A.; McFarland, K.; Dawson, A.; Hillman, K.; Barr, M.; Cardona, M. End-of-life priorities of older adults with terminal illness and caregivers: A qualitative consultation. Health Expect. 2019, 22, 405-414. [CrossRef]

50. Sealey, M.; O'Connor, M.; Aoun, S.M.; Breen, L.J. Exploring barriers to assessment of bereavement risk in palliative care: Perspectives of key stakeholders. BMC Palliat. Care 2015, 14, 49. [CrossRef]

51. Sneesby, L.; Satchell, R.; Good, P.; van der Riet, P. Death and dying in Australia: Perceptions of a Sudanese community. J. Adv. Nurs. 2011, 67, 2696-2702. [CrossRef]

52. Tan, H.M.; O'Connor, M.M.; Miles, G.; Klein, B.; Schattner, P. GP and nurses' perceptions of how after hours care for people receiving palliative care at home could be improved: A mixed methods study. BMC Palliat. Care 2009, 8, 13. [CrossRef]

53. Wiese, M.; Stancliffe, R.J.; Balandin, S.; Howarth, G.; Dew, A. End-of-life care and dying: Issues raised by staff supporting older people with intellectual disability in community living services. J. Appl. Res. Intellect. Disabil. 2012, 25, 571-583. [CrossRef]

54. You, J.J.; Dodek, P.; Lamontagne, F.; Downar, J.; Sinuff, T.; Jiang, X.; Day, A.G.; Heyland, D.K. What really matters in end-of-life discussions? Perspectives of patients in hospital with serious illness and their families. CMAJ 2014, 186, E679-E687. [CrossRef]

55. Simon, J.; Porterfield, P.; Bouchal, S.R.; Heyland, D. 'Not yet'and 'Just ask': Barriers and facilitators to advance care planning-A qualitative descriptive study of the perspectives of seriously ill, older patients and their families. BMJ Support. Palliat. Care 2015, 5, 54-62. [CrossRef] [PubMed]

56. Gallagher, R.; Krawczyk, M. Family members' perceptions of end-of-life care across diverse locations of care. BMC Palliat. Care 2013, 12, 25. [CrossRef] [PubMed]

57. MacLeod, A.; Skinner, M.W.; Low, E. Supporting hospice volunteers and caregivers through community-based participatory research. Health Soc. Care Community 2012, 20, 190-198. [CrossRef]

58. Maddalena, V.; O'Shea, F.; Barrett, B. An Exploration of Palliative Care Needs of People with End-Stage Renal Disease on Dialysis: Family Caregiver's Perspectives. J. Palliat. Care 2018, 33, 19-25. [CrossRef] [PubMed]

59. Mistry, B.; Bainbridge, D.; Bryant, D.; Toyofuku, S.T.; Seow, H. What matters most for end-of-life care? Perspectives from community-based palliative care providers and administrators. BMJ Open 2015, 5, e007492. [CrossRef]

60. Sarti, A.J.; Bourbonnais, F.F.; Landriault, A.; Sutherland, S.; Cardinal, P. An Interhospital, Interdisciplinary Needs Assessment of Palliative Care in a Community Critical Care Context. J. Palliat. Care 2015, 31, 234-242. [CrossRef] [PubMed]

61. Brueckner, T.; Schumacher, M.; Schneider, N. Palliative care for older people-Exploring the views of doctors and nurses from different fields in Germany. BMC Palliat. Care 2009, 8, 7. [CrossRef]

62. Geiger, K.; Schneider, N.; Bleidorn, J.; Klindtworth, K.; Jünger, S.; Müller-Mundt, G. Caring for frail older people in the last phase of life-The general practitioners' view. BMC Palliat. Care 2016, 15, 52. [CrossRef]

63. Klindtworth, K.; Oster, P.; Hager, K.; Krause, O.; Bleidorn, J.; Schneider, N. Living with and dying from advanced heart failure: Understanding the needs of older patients at the end of life. BMC Geriatr. 2015, 15, 125. [CrossRef]

64. Krug, K.; Ballhausen, R.A.; Bölter, R.; Engeser, P.; Wensing, M.; Szecsenyi, J.; Peters-Klimm, F. Challenges in supporting lay carers of patients at the end of life: Results from focus group discussions with primary healthcare providers. BMC Fam. Pract. 2018, 19, 112. [CrossRef]

65. Weber, M.; Claus, M.; Zepf, K.I.; Fischbeck, S.; Pinzon, L.C.E. Dying in Germany-Unfulfilled needs of relatives in different care settings. J. Pain Symptom Manag. 2012, 44, 542-551. [CrossRef] [PubMed]

66. Ziehm, J.; Farin, E.; Schäfer, J.; Woitha, K.; Becker, G.; Köberich, S. Palliative care for patients with heart failure: Facilitators and barriers-A cross sectional survey of German health care professionals. BMC Health Serv. Res. 2016, 16, 361. [CrossRef] [PubMed]

67. Den Herder-van der Eerden, M.; van Wijngaarden, J.; Payne, S.; Preston, N.; Linge-Dahl, L.; Radbruch, L.; Van Beek, K.; Menten, J.; Busa, C.; Csikos, A.; et al. Integrated palliative care is about professional networking rather than standardisation of care: A qualitative study with healthcare professionals in 19 integrated palliative care initiatives in five European countries. Palliat. Med. 2018, 32, 1091-1102. [CrossRef] [PubMed]

68. Goodman, C.; Evans, C.; Wilcock, J.; Froggatt, K.; Drennan, V.; Sampson, E.; Iliffe, S. End of life care for community dwelling older people with dementia: An integrated review. Int. J. Geriatr. Psychiatry 2010, 25, 329-337. [CrossRef]

69. Higginson, I.J.; Daveson, B.A.; Morrison, R.; Deokhee, Y.; Meier, D.; Smith, M.; Ryan, K.; McQuillan, R.; Johnston, B.; Normand, C. Social and clinical determinants of preferences and their achievement at the end of life: Prospective cohort study of older adults receiving palliative care in three countries. BMC Geriatr. 2017, 17, 271. [CrossRef]

70. Ke, L.-S.; Huang, X.; Hu, W.-Y.; O'Connor, M.; Lee, S. Experiences and perspectives of older people regarding advance care planning: A meta-synthesis of qualitative studies. Palliat. Med. 2017, 31, 394-405. [CrossRef]

71. Low, J.; Pattenden, J.; Candy, B.; Beattie, J.; Jones, L. Palliative care in advanced heart failure: An international review of the perspectives of recipients and health professionals on care provision. J. Card. Fail. 2011, 17, 231-252. [CrossRef]

72. Selman, L.; Brighton, L.; Sinclair, S.; Karvinen, I.; Egan, R.; Speck, P.; Powell, R.; Deskur-Smielecka, E.; Glajchen, M.; Adler, S.; et al. Patients' and caregivers' needs, experiences, preferences and research priorities in spiritual care: A focus group study across nine countries. Palliat. Med. 2018, 32, 216-230. [CrossRef]

73. Smallwood, N.; Currow, D.; Booth, S.; Spathis, A.; Irving, L.; Philip, J. Attitudes to specialist palliative care and advance care planning in people with COPD: A multi-national survey of palliative and respiratory medicine specialists. BMC Palliat. Care 2018, 17, 115. [CrossRef] 
74. Virdun, C.; Luckett, T.; Davidson, P.; Phillips, J. Dying in the hospital setting: A systematic review of quantitative studies identifying the elements of end-of-life care that patients and their families rank as being most important. Palliat. Med. 2015, 29, 774-796. [CrossRef]

75. Scheerens, C.; Deliens, L.; Van Belle, S.; Joos, G.; Pype, P.; Chambaere, K. "A palliative end-stage COPD patient does not exist": A qualitative study of barriers to and facilitators for early integration of palliative home care for end-stage COPD. NPJ Prim. Care Resp. Med. 2018, 28, 23. [CrossRef] [PubMed]

76. Siouta, N.; Clement, P.; Aertgeerts, B.; Van Beek, K.; Menten, J. Professionals' perceptions and current practices of integrated palliative care in chronic heart failure and chronic obstructive pulmonary disease: A qualitative study in Belgium. BMC Palliat. Care 2018, 17, 103. [CrossRef] [PubMed]

77. Udo, C.; Neljesjö, M.; Strömkvist, I.; Elf, M. A qualitative study of assistant nurses' experiences of palliative care in residential care. Nurs. Open 2018, 5, 527-535. [CrossRef] [PubMed]

78. Wallerstedt, B.; Benzein, E.; Schildmeijer, K.; Sandgren, A. What is palliative care? Perceptions of healthcare professionals. Scand. J. Caring Sci. 2019, 33, 77-84. [CrossRef]

79. Pennbrant, S.; Hjorton, C.; Nilsson, C.; Karlsson, M. “The challenge of joining all the pieces together" -Nurses' experience of palliative care for older people with advanced dementia living in residential aged care units. J. Clin. Nurs. 2020, 29, 3835-3846. [CrossRef]

80. Carvalho, G.A.F.D.L.; Menezes, R.M.P.D.; Enders, B.C.; Teixeira, G.A.; Dantas, D.N.A.; Oliveira, D.R.C.D. Meanings attributed to palliative care by health professional in the primary care context1. Texto Contexto Enferm. 2018, 27, e5740016. [CrossRef]

81. Fan, S.; Lin, I.; Hsieh, J.; Chang, C. Psychosocial care provided by physicians and nurses in palliative care: A mixed methods study. J. Pain Symptom Manag. 2017, 53, 216-223. [CrossRef]

82. Lenherr, G.; Meyer-Zehnder, B.; Kressig, R.; Reiter-Theil, S. To speak, or not to speak-do clinicians speak about dying and death with geriatric patients at the end of life? Swiss Med. Wkly. 2012, 142, w13563. [CrossRef]

83. Bolt, E.; Pasman, H.; Willems, D.; Onwuteaka-Philipsen, B. Appropriate and inappropriate care in the last phase of life: An explorative study among patients and relatives. BMC Health Serv. Res. 2016, 16, 655. [CrossRef]

84. Bijnsdorp, F.M.; Onwuteaka-Philipsen, B.D.; Boot, C.R. Combining paid work and family care for a patient at the end of life at home: Insights from a qualitative study among caregivers in the Netherlands. BMC Palliat. Care 2021, 2021 93, 20. [CrossRef]

85. Midtbust, H.; Alnes, R.; Gjengedal, E.; Lykkeslet, E. Perceived barriers and facilitators in providing palliative care for people with severe dementia: The healthcare professionals' experiences. BMC Health Serv. Res. 2018, 18, 709. [CrossRef] [PubMed]

86. Fryer, S.; Bellamy, G.; Morgan, T.; Gott, M. "Sometimes I've gone home feeling that my voice hasn't been heard": A focus group study exploring the views and experiences of health care assistants when caring for dying residents. BMC Palliat. Care 2016, 15, 1-9. [CrossRef] [PubMed]

87. Mousing, C.; Timm, H.; Lomborg, K.; Kirkevold, M. Barriers to palliative care in people with chronic obstructive pulmonary disease in home care: A qualitative study of the perspective of professional caregivers. J. Clin. Nurs. 2018, 27, 650-660. [CrossRef] [PubMed]

88. Chan, H.Y.L.; Chan, C.N.C.; Man, C.W.; Chiu, A.D.W.; Liu, F.C.; Leung, E.M.F. Key Components for the Delivery of Palliative and End-of-Life Care in Care Homes in Hong Kong: A Modified Delphi Study. Int. J. Environ. Res. Public Health 2022, $19,667$. [CrossRef]

89. Barclay, S.; Momen, N.; Case-Upton, S.; Kuhn, I.; Smith, E. End-of-life care conversations with heart failure patients: A systematic literature review and narrative synthesis. Br. J. Gen. Pract. 2011, 61, e49-e62. [CrossRef]

90. De Witt Jansen, B.; Brazil, K.; Passmore, P.; Buchanan, H.; Maxwell, D.; McIlfatrick, S.J.; Morgan, S.M.; Watson, M.; Parsons, C. 'There's a Catch-22' - The complexities of pain management for people with advanced dementia nearing the end of life: A qualitative exploration of physicians' perspectives. Palliat. Med. 2017, 31, 734-742. [CrossRef]

91. Hennings, J.; Froggatt, K.; Keady, J. Approaching the end of life and dying with dementia in care homes: The accounts of family carers. Rev. Clin. Gerontol. 2010, 20, 114-127. [CrossRef]

92. Aebischer, S.; Nikolic, R.; Lazic, R.; Dropic, T.; Vogel, B.; Lab, S.; Lachat, P.; Hudelson, C.; Matis, S. Addressing the needs of terminally-ill patients in Bosnia-Herzegovina: Patients' perceptions and expectations. BMC Palliat. Care 2018, 17, 123. [CrossRef]

93. Raymond, M.; Warner, A.; Davies, N.; Iliffe, S.; Manthorpe, J.; Ahmedzhai, S. Palliative care services for people with dementia: A synthesis of the literature reporting the views and experiences of professionals and family carers. Dementia 2014, 13, 96-110. [CrossRef]

94. Hill, S.; Mason, H.; Poole, M.; Vale, L.; Robinson, L. What is important at the end of life for people with dementia? The views of people with dementia and their carers. Int. J. Geriatr. Psychiatry 2016, 32, 1037-1045. [CrossRef]

95. Motamedi, M.; Brandenburg, C.; Bakhit, M. Concerns and potential improvements in end-of-life care from the perspectives of older patients and informal caregivers: A scoping review. BMC Geriatr. 2021, 21, 729. [CrossRef] [PubMed]

96. Steindal, S.A.; Nes, A.A.G.; Godskesen, T.E.; Dihle, A.; Lind, S.; Winger, A.; Klarare, A. Patients' experiences of telehealth in palliative home care: Scoping review. J. Med. Intern. Res. 2020, 22, 16218. [CrossRef] [PubMed]

97. Mathews, J.; Hannon, B.; Zimmermann, C. Models of Integration of Specialized Palliative Care with Oncology. Curr. Treat. Options Oncol. 2021, 22, 44. [CrossRef] [PubMed]

98. Gijsberts, M.; Liefbroer, A.; Otten, R.; Olsman, E. Spiritual Care in Palliative Care: A Systematic Review of the Recent European Literature. Med. Sci. 2019, 7, 25. [CrossRef] 